\title{
Ligand Exchange Processes on Solvated Lithium Cations. VI. Determination of Coordination Numbers by Ligand Substitution and ${ }^{7} \mathrm{Li}$ NMR
}

\author{
Matthias Schmeisser ${ }^{\mathrm{a}}$, Achim Zahl ${ }^{\mathrm{a}}$, Andreas Scheurer ${ }^{\mathrm{a}}$, Ralph Puchta ${ }^{\mathrm{a}, \mathrm{b}}$, \\ and Rudi van Eldik ${ }^{\mathrm{a}}$ \\ ${ }^{a}$ Inorganic Chemistry, Department of Chemistry and Pharmacy, University of Erlangen-Nürnberg, \\ Egerlandstraße 1, 91058 Erlangen, Germany \\ b Computer-Chemistry-Center, Department of Chemistry and Pharmacy, University of Erlangen- \\ Nürnberg, Nägelsbachstraße 25, 91052 Erlangen, Germany
}

Reprint requests to Ralph Puchta. E-mail: Ralph.Puchta@chemie.uni-erlangen.de or Rudi van Eldik. E-mail: vaneldik@ chemie.uni-erlangen.de

Z. Naturforsch. 2010, 65b, 405 -413; received December 4, 2009

Dedicated to Professor Rolf W. Saalfrank on the occasion of his $70^{\text {th }}$ birthday

\begin{abstract}
On the basis of ${ }^{7} \mathrm{Li}$ NMR studies the coordination mode of phenantroline (phen) and bipyridine (bipy) to $\mathrm{Li}^{+}$ions was found to be $\left[\mathrm{Li}(\text { phen })_{2}\right]^{+}$and $\left[\mathrm{Li}(\text { bipy })_{2}\right]^{+}$in the weakly coordinating solvent nitromethane. A large chemical shift of the ${ }^{7} \mathrm{Li}$ signal indicated a strong interaction between the ligand and the metal center. The related $s p^{2}$-hybridized N-donor ligand 2,2'-bis[(4S)-4-benzyl-2oxazoline] (biox) showed a negligible effect on the ${ }^{7} \mathrm{Li}$ shift, suggesting that almost no interaction occurs between the $\mathrm{Li}^{+}$center and biox as compared to $\mathrm{Li}^{+}$and the solvent $\gamma$-butyrolactone. Corresponding DFT (RB3LYP/LANL2DZp) calculations have clearly indicated that the poor coordination of biox is not caused by steric effects but rather by the electronic nature of the heterocyclic biox system.
\end{abstract}

Key words: Lithium Complex Formation, ${ }^{7} \mathrm{Li}$ NMR, N Chelates, DFT Calculations

\section{Introduction}

During the past decades the inorganic chemistry community focused its attention on transition metal complexes because of their versatile application in catalysis [1], supramolecular self-assembly [2] and biomimetic chemistry [3]. Main group coordination chemistry also underwent fascinating developments in related areas $[4,5]$. Especially the numerous applications of lithium ions in supramolecular compounds and catalysts [6,7], with industrial, biomimetic and medicinal relevance, are good examples for the importance of main group metal-based coordination chemistry [8-16].

In homogeneous catalysis a detailed understanding of fundamental processes such as solvent exchange reactions, is an important prerequisite for the selection, optimization and composition of ideal solvents or solvent mixtures. This can further help to understand ligand exchange and substitution processes on metal ions in various solvent environments. In many cases, equilibria between solvents, ligands, metal centers, and other components, can generate structures as well as coordination numbers in solution which are different from those found in the solid state. Whereas $\mathrm{X}$-ray diffraction can only reveal information on solidstate structures, NMR spectroscopy offers an alternative method to study structures in solution.

Based on earlier work by Pasgreta et al. [17], it is our present aim to investigate the coordination of lithium ions by various bidentate ligands, and to determine the coordination number in solution by ${ }^{7} \mathrm{Li} \mathrm{NMR}$ measurements. We therefore studied the chemical shift of the ${ }^{7} \mathrm{Li}$ signal (abundance: $92.6 \%$ ) as a function of the added ligand concentration in reference to an external standard. In addition, quantum chemical calculations were performed in order to gain further support for the interpretation of the experimental observations.

In this study we selected the bidentate $\mathrm{N}$-donor ligands 2,2'-bipyridine (bipy) and 1,10-phenanthroline (phen). Their structural motives are commonly used in supramolecular chemistry and are components of var- 


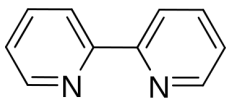

2,2'-bipyridine $=$ bipy



1,10-phenanthroline $=$ phen

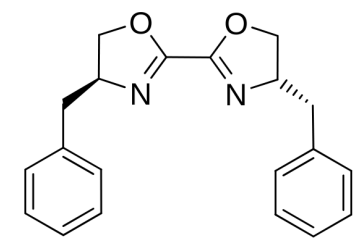

2,2'-bis[(4S)-4-benzyl-2-oxazoline]

$$
=\text { biox }
$$

Fig. 1. Structures of N,N-ligands bipy, phen, and biox.

ious bicyclic cryptands [18]. Since phen is more rigid than bipy, these ligands differ more in their flexibility than in their donor properties. As a tribute to the work of Rolf W. Saalfrank we also selected 2,2'-bis[(4S)-4benzyl-2-oxazoline] (biox) for our investigations (see Fig. 1) $[19,20]$. This biox ligands is a well known ligand in catalysis $[20,21]$ and of particular interest in this study for a number of reasons: i) this ligand contains $\mathrm{N}$ - and $\mathrm{O}$-donor atoms and therefore offers two possible coordination modes; ii) because of its $C_{2}$ symmetry, this ligand has a chiral character; iii) the bulky benzyl groups can induce steric hindrance; iv) the Ndonor atoms are also $s p^{2}$-hybridized but not involved in aromatic electron delocalization.

\section{Experimental Section}

\section{Materials}

All chemicals used in this study were of analytical reagent grade or of the highest purity commercially available. 2,2' Bipyridine (bipy), 1,10-phenanthroline (phen), lithium perchlorate and lithium iodide were purchased from SigmaAldrich, stored under nitrogen atmosphere, and used without further purification. 2,2'-Bis[(4S)-4-benzyl-2-oxazoline] (biox) was synthesized according to a procedure described in the literature $[19,20]$. Nitromethane and $\gamma$-butyrolactone were purchased from Acros Organics, and nitromethane was purified from organic impurities as described below.

\section{Purification of nitromethane}

To a stirred 1:1 (v/v) mixture of nitromethane and diethyl ether, small pieces of dry ice were added until the temperature was well below $-60{ }^{\circ} \mathrm{C}$, and nitromethane crystallized. The resulting suspension was filtered from diethyl ether by passing it through a Büchner-type funnel covered with a filter paper and coated with dry ice powder. The crystals were washed with pre-cooled (in a dry ice-acetone mixture) diethyl ether and transferred to a round bottom flask. After melting, residues of diethyl ether and carbon dioxide were removed by bubbling nitrogen gas through the liquid. The resulting liquid was distilled twice by use of a Vigreux column and stored under nitrogen atmosphere [22].

\section{Sample preparation}

All operations were performed under nitrogen atmosphere by use of standard Schlenk techniques. In the case of bipy and phen a solution of the bidentate ligand $(1.0 \mathrm{M}$ in nitromethane) was mixed in different volume ratios with $1 \mathrm{~mL}$ of a solution of the appropriate lithium salt $(0.05 \mathrm{M}$ in nitromethane). Because of its poor solubility, biox samples were prepared by addition of $1 \mathrm{~mL}$ of a lithium perchlorate solution ( $0.05 \mathrm{M}$ in $\gamma$-butyrolactone) to various amounts of the solid ligand to obtain the appropriate molar ratios.

\section{NMR studies}

${ }^{7} \mathrm{Li}$ NMR spectra were recorded at a frequency of $155 \mathrm{MHz}$ on a Bruker Avance DRX 400WB spectrometer equipped with a superconducting BC-94/89 magnet system. In a typical experiment, $540 \mu \mathrm{L}$ of the lithium-ligand solution mixture was transferred under nitrogen atmosphere to an NMR tube, and a $1 \mathrm{~mL}$ glass capillary filled with an external standard $\left(0.1 \mathrm{M} \mathrm{LiClO}_{4}\right.$ solution in DMF) was placed inside the NMR tube. All measurements were performed at room temperature under ambient pressure.

\section{Quantum-chemical calculations}

All structures were fully optimized using the B3LYP hybrid density functional [23] and the LANL2DZ [24] basis set augmented with polarization functions (further denoted as LANL2DZp) [25,26]. All structures were characterized as minima by computation of vibrational frequencies. The GAUSSIAN 03 suite of programs was used throughout [27].

\section{Results and Discussion}

\section{Adopted method}

To determine the number of ligand molecules coordinated to the $\mathrm{Li}^{+}$ions by NMR techniques, the concentration of the appropriate lithium salt was kept constant while the concentration of the bidentate ligand was varied over a wide range. The measured chemical shift of the ${ }^{7} \mathrm{Li}$ signal was then plotted against the molar ratio of ligand: metal. When such a plot shows a remarkable discontinuity, the appropriate ligand: metal ratio can be taken as the coordination number of the ligand. In order to avoid the disturbing influence of 




Fig. 3. ${ }^{7} \mathrm{Li}$ NMR shift as a function of the ligand: $\mathrm{LiX}$ molar ratio at $25^{\circ} \mathrm{C}$ (color online). the solvent on the investigated system, an inert "noncoordinating" solvent must be used. On the other hand, typical alkali metal salts are not appreciably soluble in really inert solvents. With a Gutmann donor number of $\mathrm{DN}=2.7$, nitromethane [28] presents a good compromise for the various requirements and is supposed to interact only weakly with the $\mathrm{Li}^{+}$ions or bidentate ligands.

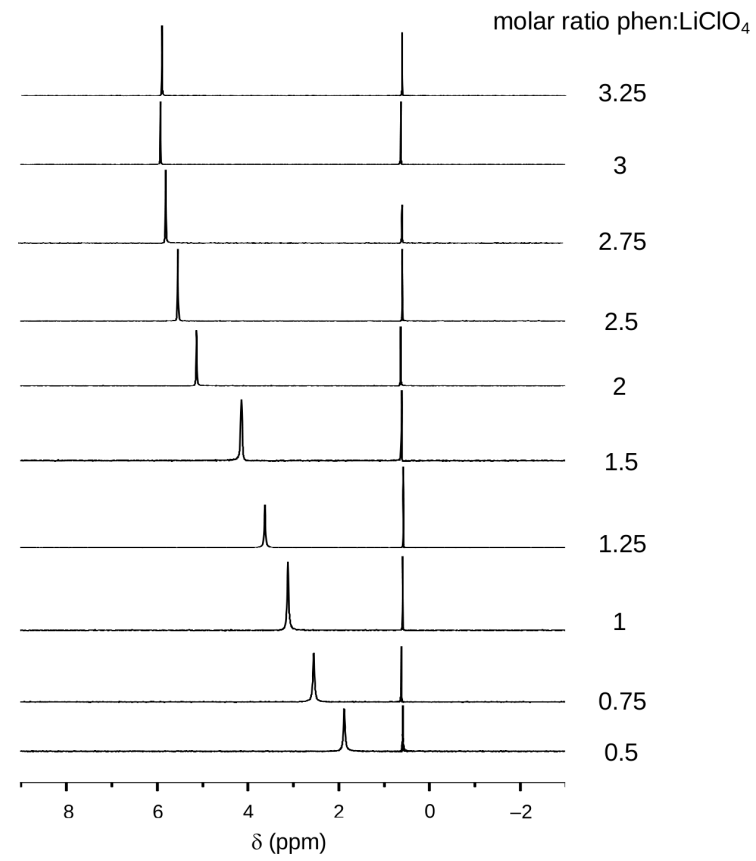

Fig. 2. ${ }^{7} \mathrm{Li}$ NMR spectra recorded as a function of the phen: $\mathrm{LiClO}_{4}$ molar ratio at $25{ }^{\circ} \mathrm{C}$ (ext. standard $0.1 \mathrm{M}$ $\mathrm{LiClO}_{4}$ in DMF).

\section{Coordination of $\mathrm{Li}^{+}$ions by phen}

As a starting point for our studies we selected the coordination of the phen ligand to $\mathrm{Li}^{+}$ions. Because of the size and the structure of the phen ligand, we expected two or not more than three ligand molecules to coordinate to $\mathrm{Li}^{+}$center. As source of $\mathrm{Li}^{+}$ions we used $\mathrm{LiClO}_{4}$ to minimize anion effects. Fig. 2 illustrates the results obtained from the ${ }^{7} \mathrm{Li}$ NMR study. The step-wise addition of phen leads to a significant down-field shift of the ${ }^{7} \mathrm{Li}$ signal, which indicates a strong coordination by the phen ligand. This behavior stops at a molar ratio of at about 2.8, after which no further shift of the ${ }^{7} \mathrm{Li}$ signal was observed. Fig. 3 shows a plot of the chemical shift as a function of the molar ratio. As indicated by the straight lines (blue color) a clear breakpoint can be observed at a molar ratio of phen to $\mathrm{Li}^{+}$of $2: 1$, which indicates that $\mathrm{Li}^{+}$is coordinated by two phen molecules under these conditions.

On the other hand, the measured chemical shift at this molar ratio is not the same as determined from the crossing point of the straight lines, so that the equilibrium between chelated and non-chelated $\mathrm{Li}^{+}$ions has to be considered (Eq. 1).

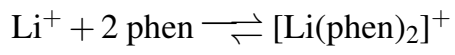

Buttery et al. recently published X-ray data for various alkaline ions coordinated by phen. In contrast to our procedure they used methanol as a solvent for the crystal growth [29]. However, they also found that two phen molecules coordinate to an $\mathrm{Li}^{+}$ion. Although the methanol molecule is known to be a good donor, 
their crystal structure astonishingly exhibits only fourcoordinate $\mathrm{Li}^{+}$. The measured $\mathrm{Li}^{+}-\mathrm{N}$ distances of 2.07 and $2.10 \AA$ are somewhat elongated compared to the calculated (B3LYP/LANL2DZp) bond length of $2.05 \AA$ (see Fig. 4). This slight difference can be attributed to the influence of proximate molecules and ions in the solid state. Unfortunately, our NMR data did not reveal any information on to which extent a solvent- or counter ion-free coordination site of $\mathrm{Li}^{+}$ is an effect of ideal crystal growth, or whether there is indeed no perchlorate anion coordinated to the $\mathrm{Li}^{+}$ cation in solution. However, on the basis of the IR and Raman spectral data reported by Chabanel et al., we can (almost) exclude $\mathrm{ClO}_{4}{ }^{-}$coordination [30]. In their spectroscopic study, it was clearly shown that the $\mathrm{ClO}_{4}{ }^{-}$counterion only coordinates in nitromethane if no stronger potential ligand is present in solution. In our case phen is clearly the strongest donor system, exhibiting $s p^{2}$-hybridized N-donor atoms.

\section{Coordination of $\mathrm{Li}^{+}$ions by bipy}

In order to clarify, whether the rigidity of the phen molecule influences the coordination pattern of the $\mathrm{Li}^{+}$ ions, and whether a more flexible ligand could provoke coordination by three ligand molecules, we repeated the experiments by using bipy as the bidentate $\mathrm{N}$-donor system. Analogous to phen, the step-wise addition of bipy to a solution of $\mathrm{LiClO}_{4}$ also led to a significant down-field shift of the ${ }^{7} \mathrm{Li}$ signal and reached a maximum at a molar ratio bipy: $\mathrm{Li}^{+}$of about $3: 1$, as shown in Fig. 3 (purple line). The crossing point of the straight lines reveals a clear discontinuity of the chemical shift at a molar ratio of bipy: $\mathrm{Li}^{+}$of $2: 1$. In

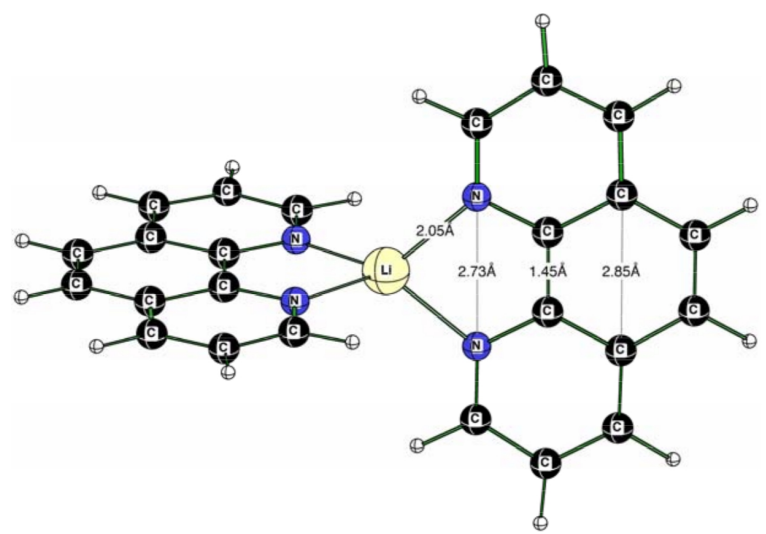

Fig. 4. Calculated (B3LYP/LANL2DZp) structure of $\left[\mathrm{Li}(\text { phen })_{2}\right]^{+}$(color online). contrast to our assumption that the $\mathrm{Li}^{+}$coordination pattern could differ when bipy instead of phen is used, the experimental results again show the coordination of only two bipy molecules to $\mathrm{Li}^{+}$ions in solution. Similar to phen, the chemical shift of the ${ }^{7} \mathrm{Li}$ signal at a molar ratio of bipy: $\mathrm{Li}^{+}$of $2: 1$ is not as large as expected by the crossing point of the straight lines. Therefore, the coordination of bipy also shows an equilibrium between chelated and non-chelated cations (Eq. 2).

$$
\mathrm{Li}^{+}+2 \text { bipy } \rightleftharpoons\left[\operatorname{Li}(\text { bipy })_{2}\right]^{+}
$$

From melts of LiI and bipy, Fischer and Hummel were able to obtain a series of compounds of the configuration $\left[\mathrm{LiI}(\text { bipy })_{x}\right]$. Among these they also reported evidence for [LiI(bipy) ${ }_{4.5}$ ] whose crystal structure exhibits $\mathrm{Li}^{+}$ions coordinated by three bipy molecules [31]. To exclude a possible disturbing effect of the $\mathrm{ClO}_{4}{ }^{-}$anion in our study, we repeated the experiment using LiI. As illustrated by Fig. 3 (green color) the chemical shift of the ${ }^{7} \mathrm{Li}$ signal shows almost the same behavior for the coordination of bipy and results in a discontinuity at a similar molar ratio of bipy: $\mathrm{Li}^{+}$. Thus, the maximum coordination of bipy to $\mathrm{LiI}$ shows the same ratio of bipy: $\mathrm{Li}^{+}$of $2: 1$ with an equilibrium between chelated and non-chelated $\mathrm{Li}^{+}$ ions. Our expectation to obtain evidence for the formation of $\left[\mathrm{Li}(\text { bipy })_{3}\right]^{+}$in solution via application of a very weak coordinating solvent, viz. nitromethane, was not achieved. Therefore, we calculated the structure of $\left[\mathrm{Li}(\text { bipy })_{2}\right]^{+}$. As expected for a higher coordination number, the average $\mathrm{Li}-\mathrm{N}$ bond length is significant longer $(2.26 \AA)$ in the crystal structure than in the calculated $\left[\mathrm{Li}(\text { bipy })_{2}\right]^{+} \operatorname{motif}(2.05 \AA)(\mathrm{B} 3 \mathrm{LYP} /$

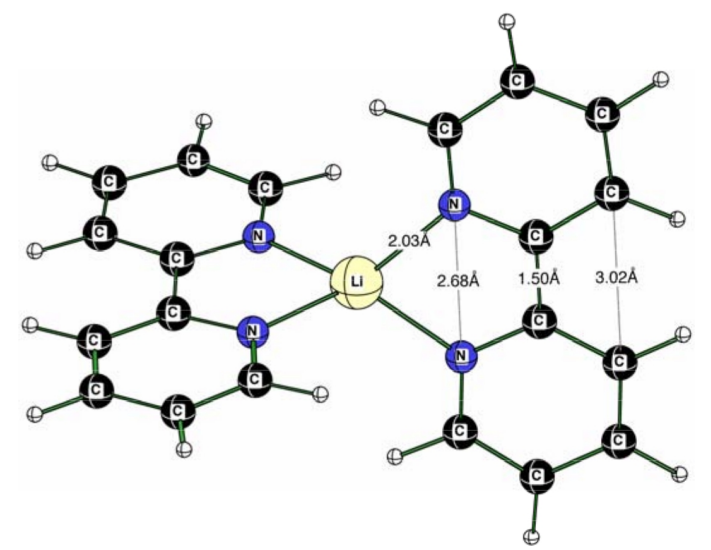

Fig. 5. Calculated (B3LYP/LANL2DZp) structure of $\left[\mathrm{Li}(\text { bipy })_{2}\right]^{+}$(color online). 




Fig. $6 .{ }^{7} \mathrm{Li}$ NMR shift as a function of the biox: $\mathrm{LiClO}_{4}$ molar ratio at $25^{\circ} \mathrm{C}$.
LANL2DZp) (see Fig. 5). Comparison of the Li-N bond lengths of $\left[\operatorname{Li}(\text { phen })_{2}\right]^{+}$and $\left[\operatorname{Li}(\text { bipy })_{2}\right]^{+}$shows that both are in the same range. In $\left[\mathrm{Li}(\text { bipy })_{2}\right]^{+}$the metal-ligand distance is $0.02 \AA$ shorter because of a shorter $\mathrm{N}-\mathrm{N}$ distance in the chelate system. This effect can be ascribed to an elongated $\mathrm{C}-\mathrm{C}$ bond between the two pyridine groups, due to the absence of a $\mathrm{HC}-\mathrm{CH}$ bridge which gives rise to $\mathrm{H}-\mathrm{H}$ repulsion in the bipy molecule (see Figs. 4 and 5) [32].

\section{Coordination of $\mathrm{Li}^{+}$ions by biox}

Although biox is mainly known as a ligand in transition metal catalysis $[20,21]$, this molecule is of special interest in the present study as it exhibits heterocyclic, $s p^{2}$-hybridized $\mathrm{N}$-donors, not involved in aromaticity. In addition, this ligand offers the possibility to study the influence of bulky groups by comparing $4,4^{\prime}, 5,5^{\prime}$ tetrahydro-2,2'-bioxazole (tbiox) with the experimentally employed biox system. In contrast to our previous experiments, we now used $\gamma$-butyrolactone as reaction medium because of the poor solubility of the biox ligand in nitromethane. With a rather low Gutmann donor number of $\mathrm{DN}=14$, we considered $\gamma$-butyrolactone not to have too much influence on the reaction system [33]. However, the experimental results have clearly revealed that the ${ }^{7} \mathrm{Li}$ signal is shifted to higher field, but shows only a very slight effect on the step-wise addition of biox to a solution of $\mathrm{LiClO}_{4}$ (Figs. 3 and 6 red dots). This indicates that the coordination of biox to $\mathrm{Li}^{+}$ions is not favorable at all, and the experimental determination of the coordination number is not possible using the ${ }^{7} \mathrm{Li}$ NMR technique.

Whereas phen and bipy can only chelate a metal ion via $\mathrm{N}$-donor atoms, the biox molecule has two possi-

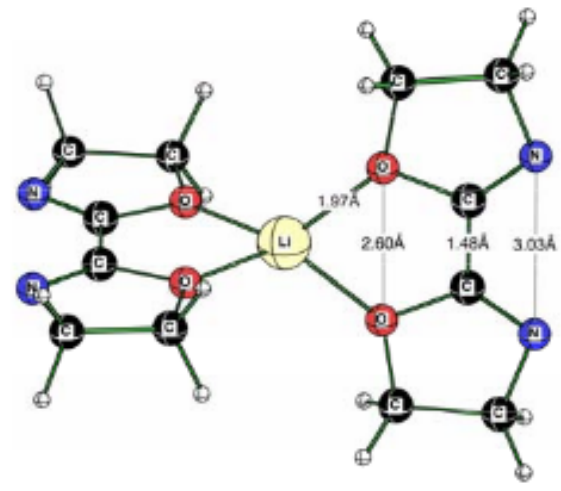

$+27.9 \mathrm{kcal} \mathrm{mol}^{-1}$

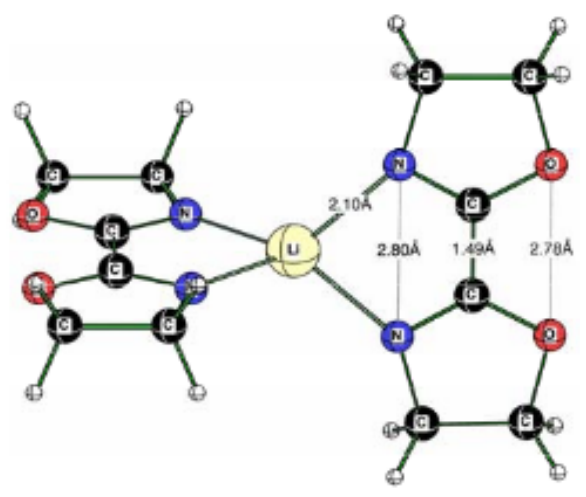

$0.0 \mathrm{kcal} \mathrm{mol}^{-1}$

Fig. 7. Calculated (B3LYP/LANL2DZp) structure of the two border line isomers of $\left[\mathrm{Li}(\text { tbiox })_{2}\right]^{+}$(color online).

ble coordination sites, viz. $\mathrm{N}$ - and O-donors. In order to clarify which coordination mode would be more favorable, we calculated the two predicted borderline cases, viz. two times N-N coordination and two times O-O co- 

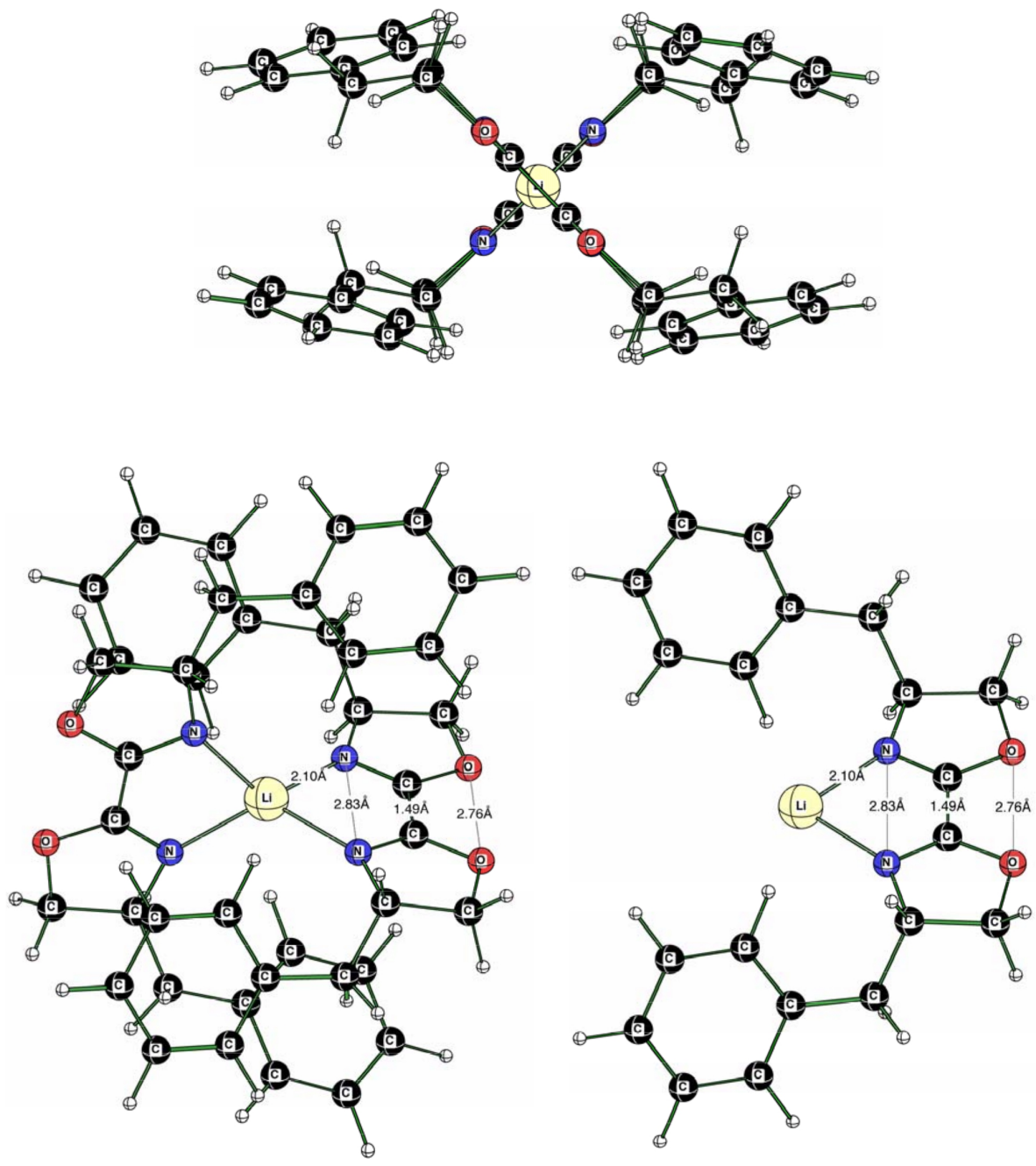

Fig. 8. Calculated (B3LYP/LANL2DZp) structures of the expected $\left[\operatorname{Li}(\text { biox })_{2}\right]^{+}$ complex observed from different views. To enable a better view of the $\left[\mathrm{Li}(\text { biox })_{2}\right]^{+}$ structure (bottom left) one biox was removed from $\left[\operatorname{Li}(\text { biox })_{2}\right]^{+}$to obtain $[\operatorname{Li}(\text { biox })]^{+}$ (bottom right; color online). ordination, respectively. As a model for the experimentally applied biox system we used tbiox since it is not affected by the sterically demanding benzyl groups. These calculations have shown a significant preference of $28 \mathrm{kcal} \mathrm{mol}^{-1}$ for $\mathrm{N}$-coordination compared to $\mathrm{O}$ coordination (see Fig. 7).

As shown in Figs. 7 and 8 the calculated structures for $\left[\mathrm{Li}(\text { tbiox })_{2}\right]^{+}$and $\left[\mathrm{Li}(\text { biox })_{2}\right]^{+}$clearly reveal identical lengths for $\mathrm{Li}-\mathrm{N}(2.10 \AA)$ and $\mathrm{C}-\mathrm{C}(1.49 \AA)$ bonds for the two heterocycles. Due to the bulkiness of the benzyl groups a slight deviation in the structure can be seen in the $\mathrm{N}-\mathrm{N}$ distances, which are $0.03 \AA$ longer in $\left[\mathrm{Li}(\text { biox })_{2}\right]^{+}$than in the tbiox model complex. Consequently, the $\mathrm{O}-\mathrm{O}$ distances are $0.2 \AA$ smaller in $\left[\operatorname{Li}(\text { biox })_{2}\right]^{+}$than in $\left[\operatorname{Li}(\text { tbiox })_{2}\right]^{+}$. From a comparison of all structural data in Table 1 , it can be con-
Table 1. Calculated (B3LYP/LANL2DZp) bond lengths in $\left[\operatorname{Li}(\text { phen })_{2}\right]^{+},\left[\operatorname{Li}(\text { bipy })_{2}\right]^{+},\left[\operatorname{Li}(\text { tbiox })_{2}\right]^{+}$and $\left[\operatorname{Li}(\text { biox })_{2}\right]^{+}$.

\begin{tabular}{lllll}
\hline & {$\left[\operatorname{Li}(\text { phen })_{2}\right]^{+}$} & $\left.[\text {Li(bipy })_{2}\right]^{+}$ & {$\left[\operatorname{Li}(\text { tbiox })_{2}\right]^{+}$} & {$\left[\operatorname{Li}(\text { biox })_{2}\right]^{+}$} \\
\hline $\mathrm{Li}-\mathrm{N}$ & $2.05 \AA$ & $2.03 \AA$ & $2.10 \AA$ & $2.10 \AA$ \\
$\mathrm{C}-\mathrm{C}$ & $1.45 \AA$ & $1.50 \AA$ & $1.49 \AA$ & $1.49 \AA$ \\
$\mathrm{N} \cdots \mathrm{N}$ & $2.73 \AA$ & $2.68 \AA$ & $2.80 \AA$ & $2.83 \AA$ \\
\hline
\end{tabular}

cluded that the Li-N bond length has the largest value for the bioxazoline-based ligand system and can therefore be considered as the weakest interaction in all studied cases. On going from the aromatic phen and bipy systems (calculated NLMO [34] hybridization of the $\mathrm{N}$ lone pair: $s p^{2.5}$ ) to the bioxazoline-based complexes (calculated NLMO [34] hybridization: $s p^{1.8}$ ) the distances between the two chelating $\mathrm{N}$-donor atoms clearly increase. On the other hand the $\mathrm{C}-\mathrm{C}$ bonds con- 
Table 2. Calculated reaction energies (B3LYP/LANL2DZp) for the step-wise substitution of $\gamma$-butyrolactone by tbiox or biox.

\begin{tabular}{lll}
\hline Reaction & tbiox & biox \\
\hline$(3)$ & $+7.4 \mathrm{kcal} \mathrm{mol}^{-1}$ & $+6.9 \mathrm{kcal} \mathrm{mol}^{-1}$ \\
$(4)$ & $+8.7 \mathrm{kcal} \mathrm{mol}^{-1}$ & $+9.9 \mathrm{kcal} \mathrm{mol}^{-1}$ \\
$\sum$ & $+16.1 \mathrm{kcal} \mathrm{mol}^{-1}$ & $+16.8 \mathrm{kcal} \mathrm{mol}^{-1}$ \\
\hline
\end{tabular}

necting the two chelating heterocycles are not significantly affected with exception of the bridging in the phen molecule.

Although steric hindrance of the bulky benzyl groups does not influence the coordination at the $\mathrm{Li}^{+}$center, ligand exchange at the solvated complex from $\left[\mathrm{Li}(\gamma \text {-butyrolactone })_{4}\right]^{+}$via $[\mathrm{Li}(\gamma$-butyrolactone $\left.)_{2}(\mathrm{~L})\right]^{+}$to $\left[\mathrm{Li}(\mathrm{L})_{2}\right]^{+}$can still be influenced by steric hindrance. Therefore, we also focused on the relative stabilities. On the basis of reactions (3) and (4) we calculated the reaction energies for the formation of $\left[\mathrm{Li}(\mathrm{L})_{2}\right]^{+}$in $\gamma$-butyrolactone.

$$
\begin{aligned}
& {\left[\operatorname{Li}(\gamma \text {-butyrolactone })_{4}\right]^{+}+\mathrm{L} \rightarrow} \\
& {\left[\operatorname{Li}(\gamma \text {-butyrolactone })_{2}(\mathrm{~L})\right]^{+}+2 \gamma \text {-butyrolactone }} \\
& {\left[\operatorname{Li}(\gamma \text {-butyrolactone })_{2}(\mathrm{~L})\right]^{+}+\mathrm{L} \rightarrow} \\
& {\left[\operatorname{Li}(\mathrm{L})_{2}\right]^{+}+2 \gamma \text {-butyrolactone }(\mathrm{L} \text { : biox or tbiox) }}
\end{aligned}
$$

As illustrated by the data in Table 2, all reaction steps are endothermic, and the overall reaction has nearly identical values for the model tbiox and biox ligands, which again does not show any influence of the bulky benzyl groups. A reliable comparison with the formation of $\left[\mathrm{Li}(\text { phen })_{2}\right]^{+}$and $\left[\mathrm{Li}(\text { bipy })_{2}\right]^{+}$in nitromethane requires detailed knowledge about the coordination of $\mathrm{CH}_{3} \mathrm{NO}_{2}$ to $\mathrm{Li}^{+}$ions. To the best of our knowledge, there are no reliable studies on this topic. We, therefore, directly compared the chelated systems as shown in reactions (5) and (6).

$$
\begin{aligned}
& {\left[\operatorname{Li}(\text { phen })_{2}\right]^{+}+2 \text { biox } \rightarrow} \\
& {\left[\operatorname{Li}(\text { biox })_{2}\right]^{+}+2 \text { phen } \quad\left(+11.0 \mathrm{kcal} \mathrm{mol}^{-1}\right)}
\end{aligned}
$$

$$
\begin{aligned}
& {\left[\operatorname{Li}(\text { bipy })_{2}\right]^{+}+2 \text { biox } \rightarrow} \\
& {\left[\operatorname{Li}(\text { biox })_{2}\right]^{+}+2 \text { bipy } \quad\left(+9.5 \mathrm{kcal} \mathrm{mol}^{-1}\right)}
\end{aligned}
$$

Again the bioxazoline-based compounds are clearly disfavored, most probably because of the different electronic nature of the ring systems, i. e. cyclic electron delocalization in the case of the six-membered rings and two double bonds in the case of the fivemembered ring systems.

\section{Conclusions}

The results obtained from our ${ }^{7} \mathrm{Li}$ NMR studies clearly demonstrate that $\mathrm{Li}^{+}$ions in a weakly coordinating solvent like nitromethane are chelated by two phen or bipy molecules. The large chemical shift of the ${ }^{7} \mathrm{Li}$ signal confirms a strong interaction between the ligand and the metal center. A completely different behavior was found for the investigated biox system, where the effect on the ${ }^{7} \mathrm{Li}$ shift is almost negligible, suggesting that the interaction between the $\mathrm{Li}^{+}$ center and biox can hardly compete with the stronger interactions between $\mathrm{Li}^{+}$and $\gamma$-butyrolactone. This is in agreement with the results from DFT calculations, which clearly indicate that the non-favored coordination of biox is not caused by steric effects but rather by the different electronic nature of the heterocyclic systems.

\section{Acknowledgements}

The authors gratefully acknowledge financial support from the Deutsche Forschungsgemeinschaft through SPP 1191 (Ionic Liquids). We would like to thank Prof. T. Clark for hosting this work in the CCC and the Regionales Rechenzentrum Erlangen (RRZE) for a generous allotment of computer time.
[1] For asymmetric epoxidation, see: a) E. N. Jacobsen, M. H. Wu, in Comprehensive Asymmetric Catalysis (Eds.: E. N. Jacobsen, A. Pfaltz, H. Yamamoto), Springer Verlag, Berlin, 1999, p. 649; b) T. Katsuki, Adv. Synth. Catal. 2002, 344, $131-147$; c) E. M. McGarrigle, D. G. Gilheany, Chem. Rev. 2005, 105, $1563-1602$; d) A. Scheurer, P. Mosset, M. Spiegel,
R. W. Saalfrank, Tetrahedron 1999, 55, $1063-1078$; e) A. Scheurer, H. Maid, F. Hampel, R. W. Saalfrank, L. Toupet, P. Mosset, R. Puchta, N. J. R. van Eikema Hommes, Eur. J. Org. Chem. 2005, 2566-2574. For asymmetric reduction of ketones, see: f) T. Ohkuma, R. Noyori, in Transition Metals for Organic Synthesis, $2^{\text {nd }}$ ed., Vol. 2, (Eds.: M. Beller, C. Bolm), Wiley-VCH, 
Weinheim, 2004, p. 29; g) R. Puchta, L. Dahlenburg, T. Clark, Chem. Eur. J. 2008, 14, 8898 - 8903.

[2] Recent publications on self-assembly, $c f$ : a) R.W. Saalfrank, H. Maid, A. Scheurer, Angew. Chem. 2008, 120, 8924-8956; Angew. Chem. Int. Ed. 2008, 47, $8794-8824$; b) R. Prakash, R. W. Saalfrank, H. Maid, A. Scheurer, F. W. Heinemann, A. X. Trautwein, L. H. Böttger, Angew. Chem. 2006, 118, 6017-6022; Angew. Chem. Int. Ed. 2006, 45, 5885-5889; c) M. D. Pluth, K. N. Raymond, Chem. Soc. Rev. 2007, 36, $161-171$; d) D. K. Chand, K. Biradha, M. Kawano, S. Sakamoto, K. Yamaguchi, M. Fujita, Chem. Asian. J. 2006, 1-2, 82-90; e) E. E. Moushi, T. C. Stamatatos, W. Wernsdorfer, V. Nastopoulos, G. Christou, A. J. Tasiopoulos, Angew. Chem. 2006, 118, $7886-$ 7889; Angew. Chem. Int. Ed. 2006, 45, 7722-7725; f) E. S. Barrett, T. J. Dale, J. Rebek, Jr., J. Am. Chem. Soc. 2007, 129, 8818-8824; g) J. Heo, Y.-M. Jeon, C. A. Mirkin, J. Am. Chem. Soc. 2007, 129, $7712-$ 7713; h) H.-B. Yang, A. M. Hawkridge, S. D. Huang, N. Das, S.D. Bunge, D.C. Muddiman, P.J. Stang, J. Am. Chem. Soc. 2007, 129, 2120-2129; i) R. M. McKinlay, J.L. Atwood, Angew. Chem. 2007, 119, 2446-2449; Angew. Chem. Int. Ed. 2007, 46, $2394-$ 2397; j) E. G. Bardají, E. Freisinger, B. Costisella, C. A. Schalley, W. Brüning, M. Sabat, B. Lippert, Chem. Eur. J. 2007, 13, 6019-6039; k) M. Shanmugam, G. Chastanet, T. Mallah, R. Sessoli, S.J. Teat, G. A. Timco, R.E.P. Winpenny, Chem. Eur. J. 2006, 12, $8777-8785$; 1) C. M. Zaleski, J. W. Kampf, T. Mallah, M. L. Kirk, V. L. Pecoraro, Inorg. Chem. 2007, 46, 1954-1956; m) H. Oshio, M. Nihei, Bull. Chem. Soc. Jpn. 2007, 80, 608-620; n) M. Albrecht, R. Fröhlich, Bull. Chem. Soc. Jpn. 2007, 80, 797 - 808; o) C. Pariya, C. R. Sparrow, C.-K. Back, G. Sandí, F. R. Fronczek, A. W. Maverick, Angew. Chem. 2007, 119, 6421-6424; Angew. Chem. Int. Ed. 2007, 46, $6305-$ 6308; p) R.W. Saalfrank, U. Reimann, A. Scheurer, F. Hampel, C. Goebel, R. Herbst-Irmer, Z. Naturforsch. 2009, 64b, 365 - 370; q) G. Aromí, P. Gamez, J. Reedijk, Coord. Chem. Rev. 2008, 252, 964-989.

[3] a) A. Dees, A. Zahl, R. Puchta, N. J. R. van Eikema Hommes, F. W. Heinemann, I. Ivanović-Burmazović, Inorg. Chem. 2007, 46, 2459-2470; b) D. Sarauli, V. Popova, A. Zahl, R. Puchta, I. Ivanović-Burmazović, Inorg. Chem. 2007, 46, 7480 - 7860; c) M. Schmeisser, R. van Eldik, Inorg. Chem. 2009, 48, 7466-7475; d) I. Ivanović-Burmazović, Adv. Inorg. Chem. 2008, 60, 59 - 100; e) I. Ivanović-Burmazović, R. van Eldik, Dalton Trans. 2008, 5259-5275.

[4] For main group elements in catalysis, see: a) J. Spielmann, G. Jansen, H. Bandmann, S. Harder, Angew. Chem. 2008, 120, 6386-6391; Angew. Chem. Int. Ed. 2008, 47, 6290-6295; b) L. Orzechowski, D. Piesik,
C. Ruspic, S. Harder, Dalton Trans. 2008, 4742 -4746; c) L. Orzechowski, S. Harder, Organometallics 2007, 26, 2144-2148.

[5] For ion recognition in supramolecular systems, see: a) R. W. Saalfrank, H. Maid, A. Scheurer, F. W. Heinemann, R. Puchta, W. Bauer, D. Stern, D. Stalke, Angew. Chem. 2008, 120, 9073 -9077; Angew. Chem. Int. Ed. 2008, 47, 8941 - 8945; b) R. W. Saalfrank, A. Scheurer, R. Puchta, F. Hampel, H. Maid, F. W. Heinemann, Angew. Chem. 2007, 119, 269-272; Angew. Chem. Int. Ed. 2007, 46, 265-268; c) R. Puchta, B. Roling, A. Scheurer, V. Weiskopf, F. Hampel, N. J. R. van Eikema Hommes, H.-U. Hummel, Solid State Ionics 2008, 179, 489-494; d) R.W. Saalfrank, N. Mooren, A. Scheurer, H. Maid, F. W. Heinemann, F. Hampel, W. Bauer, Eur. J. Inorg. Chem. 2007, 4815-4822; e) R.W. Saalfrank, C. Deutscher, H. Maid, A.M. Ako, S. Sperner, T. Nakajima, W. Bauer, F. Hampel, B. A. Heß, N. J.R. van Eikema Hommes, R. Puchta, F. W. Heinemann, Chem. Eur. J. 2004, 10, 1899-1905; f) M. Galle, R. Puchta, N. J. R. van Eikema Hommes, R. van Eldik, Z. Phys. Chem. 2006, 220, 511-523.

[6] a) R.W. Saalfrank, O. Struck, M. G. Davidson, R. Snaith, Chem. Ber. 1994, 127, 2489-2492; b) R. W. Saalfrank, C. Spitzlei, A. Scheurer, H. Maid, F.W. Heinemann, F. Hampel, Chem. Eur. J. 2008, 14, $1472-$ 1481.

[7] a) M. Albrecht, S. Dehn, R. Fröhlich, Angew. Chem. 2006, 118, 2858-2860; Angew. Chem. Int. Ed. 2006, 45, 2792-2794; b) M. Albrecht, O. Blau, H. Röttele, New J. Chem. 2000, 24, 619-622.

[8] R. Puchta, R. van Eldik, Z. Anorg. Allg. Chem. 2008, 634, $1915-1920$.

[9] K. Dehnicke, B. Neumüller, Z. Anorg. Allg. Chem. 2008, 634, 2703-2728.

[10] P. Illner, R. Puchta, W. Schiessl, Unterricht Chemie 2007, 18, 4-8.

[11] a) C. R. Mariappan, G. Govindaraj, B. Roling, Solid State Ionics 2005, 176, 723-729; b) T. Frömling, M. Kunze, M. Schönhoff, J. Sundermeyer, B. Roling, J. Phys. Chem. B 2008, 112, 12985 -12990; c) A. Taskiran, A. Schirmeisen, H. Fuchs, H. Bracht, B. Roling, Phys. Chem. Chem. Phys. 2009, 11, 5499-5505.

[12] R. Bauer, Chem. Unserer Zeit 1985, 19, 167-173.

[13] J. Cade, Med. J. Australia 1949, 36, 349-352.

[14] N. J. Birch, Chem. Rev. 1999, 99, 2659-2682.

[15] B. Müller-Oerlinghausen, W. Greil, A. Berghöfer (Eds.), Die Lithiumtherapie, Springer Verlag, Berlin, 1997.

[16] J. Deberitz, G. Boche, Chem. Unserer Zeit 2003, 37, $258-266$.

[17] a) E. Pasgreta, R. Puchta, A. Zahl, R. van Eldik, Eur. J. Inorg. Chem. 2007, 1815-1822; b) E. Pasgreta, R. Puchta, M. Galle, N.J.R. van Eikema Hommes, 
A. Zahl, R. van Eldik, ChemPhysChem 2007, 8, 1315 1320; c) E. Pasgreta, R. Puchta, A. Zahl, R. van Eldik, Eur. J. Inorg. Chem. 2007, $3067-3076$.

[18] a) R. Puchta, R. van Eldik, Eur. J. Inorg. Chem. 2007, $1120-1127$; b) R. Puchta, R. van Eldik, J. Incl. Phenom. Macrocycl. Chem. 2008, 60, 383-392, and refs. cited there.

[19] This ligand was prepared in large scale for comparison reasons of L-tartaric acid-based analogous ligands for the asymmetric cyclopropanation: a) A. Scheurer, Dissertation, Universität ErlangenNürnberg, 2001; b) R. Boulch, A. Scheurer, P. Mosset, R. W. Saalfrank, Tetrahedron Lett. 2000, 41, 1023 - 1026; c) A. Scheurer, P. Mosset, R.W. Saalfrank, Tetrahedron: Asymmetry 1999, 10, 35593570 .

[20] a) D. Müller, G. Umbricht, B. Weber, A. Pfaltz, Helv. Chim. Acta 1991, 74, $232-240$.

[21] a) G. Helmchen, A. Krotz, K. T. Ganz, D. Hansen, Synlett 1991, 257-259; b) Y. Ukaji, M. Miyamoto, M. Mikuni, S. Takeuchi, K. Inomata, Bull. Chem. Soc. Jpn. 1996, 69, 735 -742; c) S. E. Denmark, R. A. Stavenger, A.-M. Faucher, J. P. Edwards, J. Org. Chem. 1997, 62, 3375-3389.

[22] J. F. Coetzee, T. H. Chang, Pure Appl. Chem. 1986, 58, $1541-1545$.

[23] a) A.D. Becke, J. Phys. Chem. 1993, 97, 56485652; b) C. Lee, W. Yang, R. G. Parr, Phys. Rev. B 1988, 37, 785 - 789; c) P. J. Stephens, F. J. Devlin, C. F. Chabalowski, M. J. Frisch, J. Phys. Chem. 1994, 98, $11623-11627$.

[24] a) P. J. Hay, W. R. Wadt, J. Chem. Phys. 1985, 82, 270 283; b) P. J. Hay, W. R. Wadt, J. Chem. Phys. 1985, 82, $284-298$; c) P. J. Hay, W. R. Wadt, J. Chem. Phys. 1985, 82, 299-310.

[25] S. Huzinaga (Ed.), Gaussian Basis Sets for Molecular Calculations, Elsevier, Amsterdam, 1984.

[26] The performance of this method is well documented, $c f:$ a) S. Klaus, H. Neumann, H. Jiao, A. Jacobi von Wangelin, D. Gördes, D. Strübing, S. Hübner, M. Hately, C. Weckbecker, K. Huthmacher, T. Riermeier, M. Beller, J. Organomet. Chem. 2004, 689, $3685-3700$; b) P. Illner, A. Zahl, R. Puchta, N. J. R. van Eikema Hommes, P. Wasserscheid, R. van Eldik, J. Organomet. Chem. 2005, 690, 3567-3576; c) R. Puchta, R. Meier, N. J. R. van Eikema Hommes, R. van Eldik, Eur. J. Inorg. Chem. 2006, 4063-4067; d) R. Puchta, R. Meier, R. van Eldik, Aust. J. Chem.
2007, 60, 889-897; e) P. Illner, R. Puchta, F.W. Heinemann, R. van Eldik, Dalton Trans. 2009, $2795-$ 2801; f) T. Soldatović, M. Shoukry, R. Puchta, Ž. D. Bugarčić, R. van Eldik, Eur. J. Inorg. Chem. 2009, $2261-2270$.

[27] M. J. Frisch, G. W. Trucks, H. B. Schlegel, G. E. Scuseria, M. A. Robb, J. R. Cheeseman, J. A. Montgomery, Jr., T. Vreven, K. N. Kudin, J.C. Burant, J. M. Millam, S. S. Iyengar, J. Tomasi, V. Barone, B. Mennucci, M. Cossi, G. Scalmani, N. Rega, G. A. Petersson, H. Nakatsuji, M. Hada, M. Ehara, K. Toyota, R. Fukuda, J. Hasegawa, M. Ishida, T. Nakajima, Y. Honda, O. Kitao, H. Nakai, M. Klene, X. Li, J.E. Knox, H.P. Hratchian, J.B. Cross, V. Bakken, C. Adamo, J. Jaramillo, R. Gomperts, R. E. Stratmann, O. Yazyev, A. J. Austin, R. Cammi, C. Pomelli, J.W. Ochterski, P. Y. Ayala, K. Morokuma, G. A. Voth, P. Salvador, J. J. Dannenberg, V. G. Zakrzewski, S. Dapprich, A. D. Daniels, M. C. Strain, O. Farkas, D. K. Malick, A.D. Rabuck, K. Raghavachari, J. B. Foresman, J. V. Ortiz, Q. Cui, A. G. Baboul, S. Clifford, J. Cioslowski, B. B. Stefanov, G. Liu, A. Liashenko, P. Piskorz, I. Komaromi, R. L. Martin, D. J. Fox, T. Keith, M. A. Al-Laham, C. Y. Peng, A. Nanayakkara, M. Challacombe, P. M. W. Gill, B. Johnson, W. Chen, M. W. Wong, C. Gonzalez, J. A. Pople, GAUSSIAN 03 (revision C.02), Gaussian Inc., Wallingford, CT (USA), 2004.

[28] V. Gutmann, Electrochim. Acta 1976, 21, 661 -670.

[29] J.H.N. Buttery, Effendy, G. A. Koutsantonis, S. Mutrofin, N.C. Plackett, B.W. Skelton, C. R. Whitaker, A. H. White, Z. Anorg. Allg. Chem. 2006, 632, $1829-1838$.

[30] M. Chabanel, D. Legoff, K. Touaj, J. Chem. Soc., Faraday Trans. 1996, 92, 4199-4205.

[31] E. Fischer, H.-U. Hummel, Z. Anorg. Allg. Chem. 1997, $623,483-486$.

[32] S. Grimme, C. Mück-Lichtenfeld, G. Erker, G. Kehr, H. Wang, H. Beckers, H. Willner, Angew. Chem. 2009, 121, 2629-2633; Angew. Chem. Int. Ed. 2009, 48, $2592-2595$.

[33] a) E. Pasgreta, R. Puchta, M. Galle, N. J. R. van Eikema Hommes, A. Zahl, R. van Eldik, J. Incl. Phenom. Macrocycl. Chem. 2007, 58, 81-88; b) R. Puchta, E. Pasgreta, R. van Eldik, Adv. Inorg. Chem. 2009, 61, $523-571$.

[34] A. E. Reed, L. A. Curtiss, F. Weinhold, Chem. Rev. 1988, $88,899-926$, and refs. cited therein. 